\title{
DO MERGERS IMPROVE THE X-EFFICIENCY AND SCALE EFFICIENCY OF U.S. BANKS? EVIDENCE FROM THE 1980s
}

Stavros Peristiani

\section{Federal Reserve Bank of New York Research Paper No. 9623}

August 1996

This paper is being circulated for purposes of discussion and comment only. The contents should be regarded as preliminary and not for citation or quotation without permission of the author. The views expressed are those of the author and do not necessarily reflect those of the Federal Reserve Bank of New York or the Federal Reserve System.

Single copies are available on request to:

Public Information Department

Federal Reserve Bank of New York

New York, NY 10045 
DO MERGERS IMPROVE THE X-EFFICIENCY AND SCALE

EFFICIENCY OF U.S. BANKS? EVIDENCE FROM THE 1980s*

Stavros Peristiani

Federal Reserve Bank of New York

Revised draft, June 1996

Send correspondence to: Stavros Peristiani, Research Department, Main 3 East, Federal Reserve Bank of New York, New York, NY 10045, U.S.A.

*Any views expressed in this paper are those of the author. They should not be interpreted as reflecting the views of the Federal Reserve Bank of New York or the Federal Reserve System. I. am grateful for helpful comments and suggestions received from Linda Allen, Allen Berger, and Robert DeYoung. Also, I would like to thank Valerie LaPorte and Elizabeth Miranda for their editorial comments. 


\section{ABSTRACT}

A central issue currently debated among bank analysts and economists is whether mergers enhance the efficiency of surviving banks. This paper investigates the postmerger performance of acquiring banks that participated in a merger during 1980-90. The evidence suggests that acquiring banks failed to improve postmerger X-efficiency. However, we find that acquiring banks experienced moderate gains in profitability and scale efficiency relative to a control sample. The second part of the paper uses regression analysis to identify factors influencing the performance of bank merger survivors. The regression results suggest that improvements in postmerger performance depend on the ability of the bank to strengthen asset quality. We find no evidence to support the hypothesis that in-market mergers lead to significant improvements in efficiency. 


\section{INTRODUCTION}

The banking sector went through a period of rapid consolidation and restructuring during the 1980s. Between 1980 and 1990, roughly 5,000 commercial and savings banks were taken over by other depository institutions. Consolidation has continued in the early 1990s as an onslaught of megamergers pushed the volume to record levels by 1995. Although several factors contributed to the recent surge in mergers and acquisitions, deregulation played an important role by allowing banks to expand statewide or interstate. The rapid pace of consolidation has revitalized interest in the topic and invigorated the debate over whether mergers can have a beneficial impact on U.S. banking and the public as a whole.

The McFadden Act of 1927, the Glass-Steagall Act of 1933, and the 1956 Bank Holding Company Act led to a protected and fragmented structure in U.S. banking. For years, Regulation $Q$ allowed banks to earn a fairly riskless return on assets. The gradual unraveling of some of these regulations (starting with the DIDMCA in 1980 and Garn-St Germain in 1982) created a new, more competitive environment. Many believed that overcapacity existed in the banking sector during the 1980s because banks were unable to compete on both the liability and the asset sides of their balance sheets. Following the deregulation of a the early 1980s, banks began to lose many of their high-quality corporate borrowers to the commercial paper market; furthermore, their retail deposit base was eroded by competition from money market mutual funds. As their market shares shrank, banks were faced with the choice of failing, merging with other banks, or downsizing. Yet the contraction may have had a minimal impact on overcapacity because most banks decided to entrench rather than to exit or downsize. The banks had several possible motives for doing so. Myopic bank managers may have simply overestimated their ability to compete against their rivals. In other instances, the banks may have attempted to counter their dwindling market base by enhancing their portfolio return. The regulatory framework and FDIC insurance scheme allowed some bank managers in search of greater returns to move to riskier investments.

Troubled by the long-term prospects of banks, many industry analysts and bankers 
have concluded that the commercial banking sector needs a major overhaul. Although the number of commercial and savings banks has continued to fall over time, proponents of consolidation point out that United States still has a large number of banking institutions relative to other industrial countries. As a consequence, too many banks are chasing too few customers, creating an inefficient banking system. A more concentrated banking system would allow banks to achieve economies of scale and become more cost efficient. Many industry analysts see consolidation as the most practical way to downsize. Mergers entail a major restructuring of the participating banks; thus, they provide an opportunity for drastic cuts that otherwise would not be implemented.

This view is contested by many academic economists and community bankers who point out that there is no widespread empirical support for these claims. They argue that although U.S. banks outnumber those of other industrial countries, the number of branching offices per capita is actually lower in the United States than in a number of other major developed countries. For instance, the United States has about 24 branches per 100,000 inhabitants compared with 37 branches for the United Kingdom and 76 for Germany. Most of the small banks in the United States are community banks that specialize in serving customers in small towns and farming areas, where large high-volume banks do not operate, but also compete quite effectively against large institutions in urban areas.

A question arising from this debate is whether mergers are an effective restructuring tool. One way to resolve this issue is by examining the long-term profitability, cost structure, and efficiency of merger survivors. There are basically two competing views on how bank profits and costs are determined. The structure-conduct-performance (SCP) hypothesis is an outgrowth of the early industrial organization work on market concentration. The basic notion of SCP is that market performance is influenced by firm conduct, which in turn is closely related to the underlying market structure. The traditional SCP hypothesis considers the banking industry as imperfectly competitive and expects that prices or product behavior in these markets will be related to the degree of market concentration [see Gilbert 
(1984)]. An alternative theory to the SCP paradigm asserts that bank behavior is driven by cost efficiency rather than market power and structure [Demsetz (1973)]. The literature distinguishes two types of efficiency. First, firms seek to produce at a more efficient scale point and optimal product mix, thereby achieving lower costs and higher profits. Second, firms of similar scale or scope can further improve performance by having superior management (managerial efficiency or X-efficiency). The competing theories of SCP and cost efficiency suggest two distinct ways in which consolidation could alter bank performance. According to the SCP hypothesis, mergers may increase profitability simply by allowing banks to attain more market power. In the efficiency hypothesis framework, the banking sector can gain from merger activity as more adept banks absorb poorly managed institutions or as combining institutions become more scale efficient.

The literature on economies of scale and scope for multiproduct banks is voluminous. Berger et al. (1993) provide an extensive review of papers studying efficiency issues and economies of scale and scope. Although results vary, most empirical studies conclude that economies of scale exist for small to midsize banks. ${ }^{1}$ The issue of $\mathrm{X}$-efficiency in banking has attracted considerable attention in the last few years. A study by Berger and Humphrey (1991) finds significant differences in X-efficiency among banks. The authors show that Xefficiencies tend to dominate scale and scope efficiencies. Using an econometric cost frontier approach, Mester (1993) estimates the efficiency of stock and mutual savings and loans. A recent Federal Reserve Staff Study by Rhoades (1994) provides an extensive survey of the literature investigating merger performance from 1980 to 1993 . Rhoades finds that most studies provide mixed results suggesting that bank mergers do not yield any substantial benefits. For instance, Berger and Humphrey (1992) estimate the postmerger changes in

1 Earlier studies found increasing returns to scale for banks with assets less than $\$ 100$ million. More recently, studies by Hunter et al. (1990) and Noulas et al. (1990) suggest that returns to scale can be maximized in a higher range, usually between $\$ 2$ billion and $\$ 10$ billion in total assets. 
bank performance for about 100 large bank mergers and acquisitions. They find that, on average, mergers have not resulted in any significant postmerger improvements in $\mathrm{X}$ efficiency. In a more recent paper, Shaffer (1993) uses a simulation approach to evaluate the effect of mergers on efficiency. His empirical findings suggest that interstate mergers can potentially lead to lower costs.

The recent empirical papers investigating banking consolidation concentrate on particular segments of the merger population. Some studies analyze large interstate mergers or acquisitions; other papers concentrate on takeovers of large banks. Examining just a subset of the merger population, however, could potentially lead to spurious conclusions. To understand the complexity of studying mergers, consider the case of Banc One Corporation, one of the most aggressive acquirers during the 1980s. Studies concentrating solely on large takeovers implicitly assume that all other mergers are irrelevant. Although small mergers may individually appear insignificant, collectively they may be quite important. Frequently, the impact of a selected sample of large mergers or acquisitions is evaluated at the bank holding company (BHC) level. Despite the occasional large merger or acquisition, BHCs most often tend to acquire small to midsize banks. For instance, in 1992 Banc One absorbed through its subsidiary Banc One-Youngstown Heritage Bank, a medium-sized bank in Ohio. Since Banc One participated in 40 other mergers during the period, it is unclear how this particular transaction would influence the corporation as whole. A better approach to evaluating the impact of the merger would be to examine the effect of Heritage Bank on Banc One-Youngstown.

This paper carefully considers all the aforementioned issues in investigating merger activity. The principal innovation of this study is that it accounts for all bank mergers for the years 1980-90 and analyzes the impact of mergers at the bank level. By considering all mergers in the period, we are able to compile a more accurate profile of the merger activity of each bank over time. More importantly, this paper investigates all three major categories of consolidation: intrastate mergers, BHC consolidations, and FDIC-assisted mergers. 
The paper is organized as follows. In section 2 we summarize the translog cost function, define the measures of efficiency and bank performance, and review the data. In section 3 we evaluate the postmerger performance of surviving banks. The central issue is whether merger survivors are able to maintain and enhance their long-term performance after a merger. Finally, in section 4 we use regression analysis to estimate the primary determinants of changes in the performance of merger survivors.

\section{METHODOLOGY}

This study utilizes the translog flexible functional form to estimate the cost structure of banks and derive measures of efficiency. This specification has been applied widely in the banking and finance literature. The translog model has been used to analyze the cost characteristics of depository institutions [for a survey, see Berger et al. (1993)]. We utilize a standard translog model given by:

$$
\begin{aligned}
\ln T C_{t i}=\alpha_{0} & +\sum_{k=1}^{5} \beta_{k} \ln \left(y_{k t i}\right)+\sum_{\ell=1}^{3} \alpha_{\ell} \ln \left(p_{\ell t i}\right) \\
& +0.5 \sum_{k=1}^{5} \sum_{j=1}^{5} \beta_{k j} \ln \left(y_{k t i}\right) \ln \left(y_{j t i}\right)+0.5 \sum_{\ell=1}^{3} \sum_{h=1}^{3} \alpha_{\ell h} \ln \left(p_{\ell t i}\right) \ln \left(p_{h t i}\right) \\
& +\sum_{k=1}^{5} \sum_{\ell=1}^{3} \delta_{\ell k} \ln \left(y_{k t i}\right) \ln \left(p_{\ell t i}\right)+\gamma_{1} \ln \left(z_{1 t i}\right)+\ln \left(x_{t i}\right)+u_{t i},
\end{aligned}
$$

where $x_{t i}$ represents the $\mathrm{X}$-efficiency factor and $u_{t i}$ is the random error. The current specification assumes five standard outputs and three input prices. Specifically, we let

$\mathrm{TC}=$ total cost (operating expenses + interest expenses).

$y_{k}=$ bank outputs; $(k=1)$ commercial and industrial loans, $(k=2)$ personal loans, $(k=3)$ real estate loans, $(k=4)$ retail and savings deposits, $(k=5)$ demand deposits.

$p_{\ell}=$ price of inputs; $(\ell=1)$ price of borrowed funds, $(\ell=2)$ price of capital, $(\ell=3)$ price of labor.

$z_{1}=1$ if bank is owned by a bank holding company; $=0$ otherwise. 
Table 1

Summary Statistics for Variables and Predictions

\begin{tabular}{lllllllll}
\hline Variable & & 1984 & 1985 & 1986 & 1987 & 1988 & 1989 & 1990 \\
\hline TC & Total Cost & 16.7 & 16.6 & 16.8 & 18.2 & 20.9 & 25.3 & 26.6 \\
$y_{1}$ & C\&I Loans & 39.8 & 40.8 & 43.0 & 43.9 & 46.7 & 49.2 & 50.3 \\
$y_{2}$ & Personal Loans & 18.5 & 21.6 & 23.8 & 25.8 & 29.1 & 31.5 & 32.5 \\
$y_{3}$ & Real Estate & 26.9 & 30.7 & 42.1 & 51.3 & 60.6 & 69.5 & 76.5 \\
& Loans & & & & & & & \\
$y_{4}$ & Retail and Savings & 57.3 & 63.4 & 69.5 & 73.7 & 82.6 & 101.9 & 114.6 \\
& Deposits & & & & & & & \\
$y_{5}$ & Demand Deposits & 28.8 & 31.6 & 35.7 & 33.0 & 34.7 & 35.9 & 37.2 \\
$p_{1}$ & Price of Borrowed & 0.073 & 0.065 & 0.057 & 0.051 & 0.053 & 0.059 & 0.059 \\
& Funds & & & & & & & \\
$p_{2}$ & Price of Capital & 0.277 & 0.294 & 0.304 & 0.304 & 0.303 & 0.302 & 0.299 \\
$p_{3}$ & Price of Labor & 20.7 & 21.87 & 22.84 & 23.65 & 24.633 & 25.85 & 27.10 \\
$S_{1}$ & borrowed funds & 0.737 & 0.717 & 0.699 & 0.682 & 0.691 & 0.711 & 0.712 \\
$S_{2}$ & Capital & 0.063 & 0.070 & 0.074 & 0.077 & 0.073 & 0.067 & 0.066 \\
\hline$\hat{S}_{1}$ & borrowed funds & 0.746 & 0.727 & 0.704 & 0.686 & 0.694 & 0.719 & 0.719 \\
$\hat{S}_{2}$ & Capital & 0.060 & 0.066 & 0.072 & 0.075 & 0.071 & 0.064 & 0.063 \\
\hline \hline
\end{tabular}

NOTES: All outputs are measured in $\$$ millions. 
Cost-share equations are derived from Shephard's Lemma:

$$
\frac{\partial \ln T C_{t i}}{\partial \ln \left(p_{\ell t i}\right)}=S_{\ell t i}=\alpha_{\ell}+\sum_{h=1}^{3} \alpha_{\ell h} \ln \left(p_{h t i}\right)+\sum_{k=1}^{5} \delta_{\ell k} \ln \left(y_{k t i}\right), \quad \ell=1,2
$$

Here, a share equation is omitted in order to avoid singularity.

The standard homogeneity conditions on input prices are imposed, that is, $\sum_{\ell=1}^{3} \alpha_{\ell}=1$, $\sum_{\ell=1}^{3} \alpha_{\ell h}=0$, and $\sum_{\ell=1}^{3} \delta_{\ell k}=0$, where $h=1,2,3$, and $k=1, \ldots, 5$. In addition, we impose the usual conditions of symmetry $\alpha_{\ell h}=\alpha_{h \ell}$ and $\beta_{k j}=\beta_{j k}$, where $h, \ell=1,2,3$ and $j, k=1, \ldots, 5$. We estimated the system of equations defined by equations (1) and (2) subject to homogeneity and symmetry restrictions by the method of seemingly unrelated regressions (SUR). Although call report information is available on a quarterly basis, we estimated the translog cost specification using available annual information from 1984 to 1990. More specifically, the dependent variable is given by the logarithm of total cost for the whole year. This approach provides a more stable profile of efficiency across time than does quarterly estimation. The translog model requires production to be positive for all banks. It is not unusual for small banks to have no commercial industrial loans or other defined outputs. These banks were excluded from the analysis. We should note, however, that we only lost less than one percent of the sample because most merging banks had a positive production vector.

Table 1 provides a brief summary of the variables. For the sake of brevity, the coefficients of the translog model are not reported in the paper but are available to readers on request. Overall, parameter estimates of the translog cost functions meet all regularity conditions. With the exception of a handful of outliers, marginal costs are positive. In particular, the marginal cost vector evaluated at the mean for all seven years of estimation, that is, $\partial \ln T C(\bar{y}, \bar{p}) / \partial \ln y$, is equal to $(0.086,0.068,0.085,0.418,0.258)$. Moreover, the concavity condition for all cost functions is satisfied at the point of estimation because the eigenvalues of the hessian matrix are positive. As seen for table 1, estimates of the share equations also meet all regularity conditions as nearly all predicted values of the shares are positive. Moreover, pooling again all observations, we find that the first percentile of $\hat{S}_{1}$ and 
$\hat{S}_{2}$ are 0.385 and 0.019 , respectively. Finally, we estimated the own price partial elasticities of substitution for inputs defined by:

$$
\eta_{\ell \ell}=\frac{\alpha_{\ell \ell}+S_{\ell}\left(S_{\ell}-1\right)}{S_{\ell}^{2}} \quad \quad \ell=1,2
$$

As expected, the values are negative. In particular, at the mean we estimate $\eta_{11}=-0.208$, $\eta_{22}=-12.63$, and $\eta_{33}=-1.20$.

\subsection{Measuring Bank Performance}

\section{Financial Ratios}

- The financial performance of depository institutions is often evaluated using simple ratios derived from balance sheet and income statements. Financial ratios are quite useful because they allow analysts to appraise the profitability and operational efficiency of banks relative to the underlying risks taken. Most recent studies investigating the effectiveness of bank mergers and acquisitions rely on such financial and accounting measures. Two of the most commonly utilized financial measures are: 1$)$ the return on assets $\left(\mathrm{ROA}_{t i}\right)$, computed by the ratio of after-tax net income to assets, and 2) the ratio of noninterest expenses to total assets $\left(\mathrm{NIEX}_{t i}\right)$.

Although financial ratios provide accurate measures of profitability and credit risk, some analysts have argued that these measures are very crude estimates of cost efficiency and productivity (see, for instance, Berger and Humphrey (1992)). One noted criticism is that operating cost comparisons fail to account for fluctuations in the product mix or funding mix. Operating costs account for only about 30 percent of the total bank costs. But more important, as banks grow through mergers they tend to shift to purchased funds, which are less labor intensive. As a consequence, operating costs may decline after a merger although the merger survivor has not achieved any real efficiency gains.

In light of this criticism, recent studies have shifted away from financial ratios, choosing instead to measure merger-related efficiency gains by the cost function methodology. 
Although our study focuses primarily on these efficiency measures, we also evaluate the performance of bank mergers using the standard financial ratios. Despite the above criticism, we believe that financial ratios are still useful because there is no strong evidence to suggest that mergers result in any significant shifts in the product or funding mix.

\section{X-efficiency}

In a competitive environment, a firm is considered $\mathrm{X}$-inefficient if it systematically incurs substantial and wasteful costs relative to other firms. Several econometric and linear programming techniques have been proposed for estimating $X$-efficiency. Our study utilizes a variant of the distribution-free method [see Berger (1993)]. This approach collapses the $\mathrm{X}$-efficiency and the random error component into a single variable. In the framework of equation (1), the new variable is defined by $e_{t i}=\ln \left(x_{t i}\right)+u_{t i}$. As shown by Berger, the residuals can be transformed so that the minimum is zero, that is,

$$
\hat{\varepsilon}_{t i}=\min _{i}\left\{\hat{e}_{t i}\right\}-\hat{e}_{t i}
$$

By taking the exponential of equation (3) the resulting efficiency measure

$$
\mathrm{XEFF}_{t i}=\exp \left(\hat{\varepsilon}_{t i}\right)
$$

is normalized to fall between zero and one. Since $\mathrm{XEFF}_{t i}$ is not robust to outliers, Berger suggested a modification that censors all extreme values. Observations that fall below the $p$-th percentile are set equal to the $p$-th percentile value $\left(\hat{\varepsilon}_{t}^{(p)}\right)$, and observations that exceed the $(1-p)$-th percentile are valued at $\left(\hat{\varepsilon}_{t}^{(1-p)}\right)$. More formally, the modified X-efficiency measure is defined by:

$$
\mathrm{XEFF}_{t i}(p)=\exp \left[\hat{\varepsilon}_{t}^{(p)}-\max \left\{\hat{\varepsilon}_{t}^{(p)}, \min \left\{\hat{\varepsilon}_{t i}, \hat{\varepsilon}_{t}^{(1-p)}\right\}\right]\right.
$$

This alternative form of $\mathrm{XEFF}_{t i}$ eliminates the effect of extreme outliers and allows for the possibility that several institutions can be classified into the most efficient class. Berger and Humphrey (1993) have suggested an alternative to $\operatorname{XEFF}_{t i}(p)$ that utilizes X-efficiency 
ranks rather than the actual values. This nonparametric approach is used in part because macroeconomic and regulatory changes may influence the distribution of costs such that it would not be reasonable to expect banks to maintain the same distance from the efficient frontier over time. Let $\mathrm{XEFF}_{t[i]}$ represent the order statistic of $\mathrm{XEFF}(p)$ for the $\mathrm{i}$-th bank at time $t$, where $1 \leq t[i] \leq N_{t}$. We define rank efficiency by:

$$
\operatorname{RANKXEFF}_{t i}=t[i]
$$

We computed estimates of RANKXEFF using the RANK procedure of SAS. This procedure ranks values of $\mathrm{XEFF}$ from smallest to largest, assigning the rank 1 to the least efficient bank and the rank $\mathrm{N}$ to the most efficient bank. Banks with tied values received the mean of the corresponding ranks. For simplicity, ranks were scaled between 0 and 100 .

\section{Scale Efficiency}

Most empirical studies investigating the cost structure of financial institutions estimate the optimal size by the scale elasticity of cost with respect to output, that is, $\frac{\partial \ln T C}{\partial \ln (y)}$. This approach assumes that the average cost function has a very shallow $U$-shape. The optimal value of scale elasticity represents the minimum of the U-shape average cost function. Recently, Berger (1993) and Evanoff and Israilevich (1991) have shown that the elasticity measure is not the most appropriate measure of scale efficiency. Instead, they suggest that a better estimate of scale efficiency can be derived by comparing the average cost of the scale-efficient and inefficient firms. Using this principle, Berger (1993) proposes a method for computing scale efficiency that imposes the condition that inefficient banks produce on the same expansion path as the efficient bank. In this case, multiproduct efficiency is defined by:

$$
\mathrm{SEFF}_{t i}=\exp \left[\ln T C_{t i}^{*}-\ln T C_{t i}+\ln \sum_{k=1}^{5} y_{k t i}-\ln \sum_{k=1}^{5} y_{k t i}^{*}\right]
$$

where $\left(y_{. t i}^{*}\right)$ denotes the scale-efficient vector of production for a bank producing at $\left(y_{. t i}, p_{. t i}\right)$. The variable $\mathrm{SEFF}_{t i}$ simply represents the average ray scale cost ratio between the efficient and inefficient production points. 


\subsection{Data}

We analyze merger activity by considering all 4,900 individual transactions that occurred between 1980 and 1990. A list of bank mergers is obtained from an online database maintained by the Board of Governors of the Federal Reserve System. The list of mergers is also available in printed form in Changes in Status of Banks and Branches (G.4.5 Report) under "Consolidations and Absorptions." The remaining information was compiled from the quarterly Consolidated Reports of Condition and Income, the annual Summary of Deposits, and other various sources. We classify mergers according to three basic categories. About 2,000 of the mergers in our sample are intracompany consolidations; that is, the merging banks are owned by the same BHC. A second well-defined category consists of FDIC-assisted mergers. The agency disposes failing banks in various ways. The most common method is by purchase and assumption (P\&A). In this case, the FDIC sells a package of some of the assets of the failing institution. The purchaser is required to assume a portion of the failed bank's assets and liabilities, and is given the option of a putback to the FDIC. Overall, during the 1980s the FDIC assisted in approximately 1,000 mergers. The remaining 1,900 mergers represent intrastate combinations of nonaffiliated solvent banks.

In this paper, we treat mergers and acquisitions as two distinct forms of consolidation. We define a merger as the unification of two banks under a single charter. An acquisition refers to a bank holding company's purchase of a bank that is subsequently maintained as a separate subsidiary. This paper is concerned only with bank mergers. The database of 4,900 bank mergers represents only those instances where a target's charter disappears and the target bank merges with another chartered bank. The merger database does not include $\mathrm{BHC}$ acquisitions because the acquired bank continues to function as a separately chartered bank. We should note, however, that a large fraction of $\mathrm{BHC}$ consolidations were originally $\mathrm{BHC}$ acquisitions. In this case, a $\mathrm{BHC}$ acquisition target is initially maintained as a separate subsidiary for a brief time period before it is consolidated with an affiliate.

The premerger and postmerger performance of banks is measured by an algorithm that 
selects the available financial history of the acquirer and targets up to 16 quarters before and after the merger. The algorithm is fairly complex because it has to account for the several ways a merger could occur. The most simple case is when an acquirer, which could be a unit-bank or a bank with a bank holding parent, merged only with a single bank during 1980-90. We isolated almost 1,000 cases in which the acquirer had just a single takeover. Although in theory this group provides the best framework for examining the potential effect of mergers, onetime mergers take place mainly between small banks and in aggregate represent only about 7 percent of the merger volume.

The remaining mergers are classified as multiple mergers, meaning that the acquirer has merged with more than one target during the period. Multiple mergers are more complicated because they can occur in different ways. The most straightforward case is when a bank acquires a single target each time it merges. More typically, however, we found that a multibank holding company (MBHC) absorbs another MBHC and merges all the subsidiaries of the target company with its lead bank. In this case, the algorithm treats these mergers by the same acquirer as a single merger. More precisely, suppose that an $\mathrm{MBHC}$ with a lead bank $\mathrm{A}$ acquires another MBHC that owns banks $\mathrm{B}, \mathrm{C}$, and $\mathrm{D}$. The acquired banks are treated as a single transaction, that is, the target is bank $E=B+C+D$, the acquirer is the lead bank A, and the pro forma bank is $\mathrm{A}+\mathrm{E}$. Similarly, BHC consolidations involve the simultaneous consolidation of several subsidiaries into the lead bank and therefore are treated in the same way.

Another complication arises when acquiring institutions absorb several targets in different years. We considered mergers occurring in different years as separate events. For example, if an acquirer had three different acquisitions in three different years, the algorithm constructed three different windows. Each window is studied as a different pre- and postmerger experiment. At times, a bank may have been involved in different types of mergers during the same year. For instance, during the same year a bank might consolidate several of its subsidiaries at the same time that it engaged in several intrastate mergers. In 
Figure 1

\section{A. X-Efficiency}

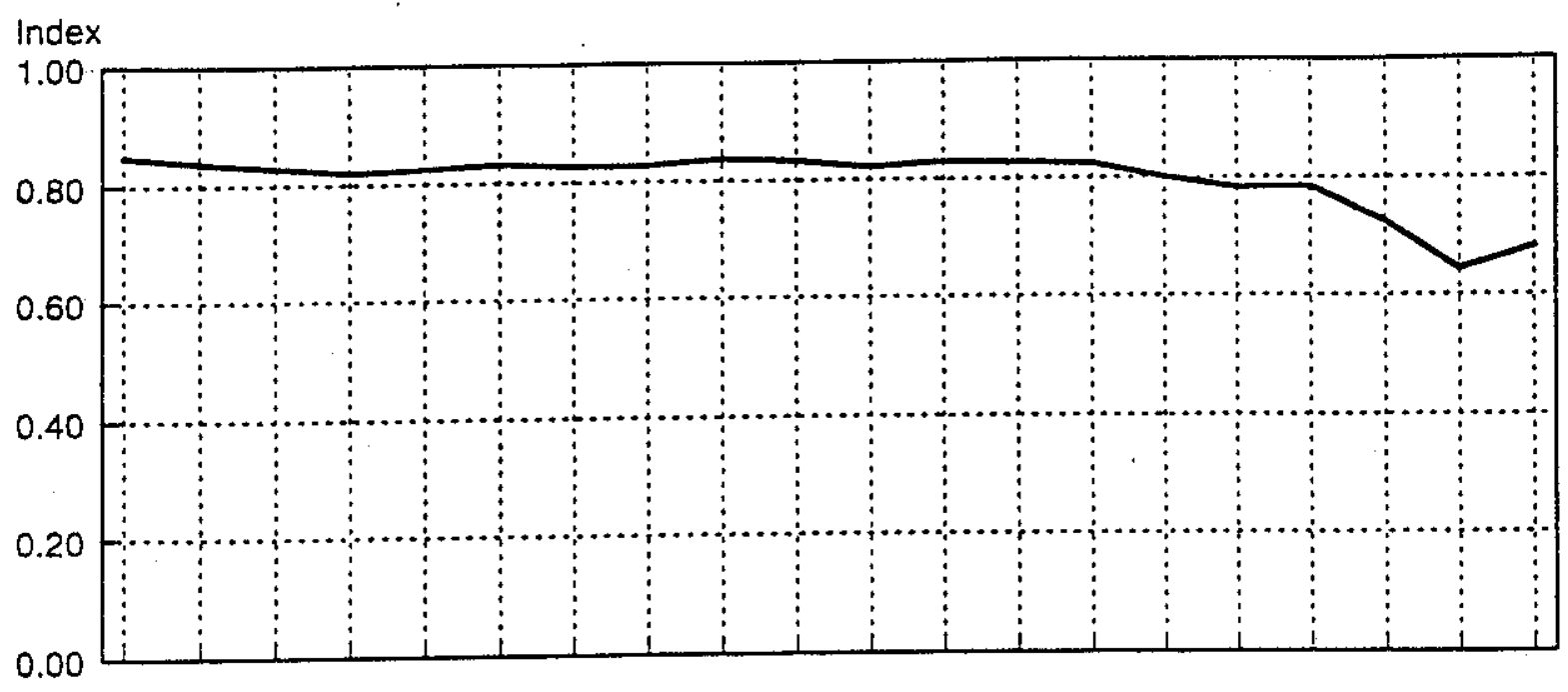

\section{B. Scale Efficiency}

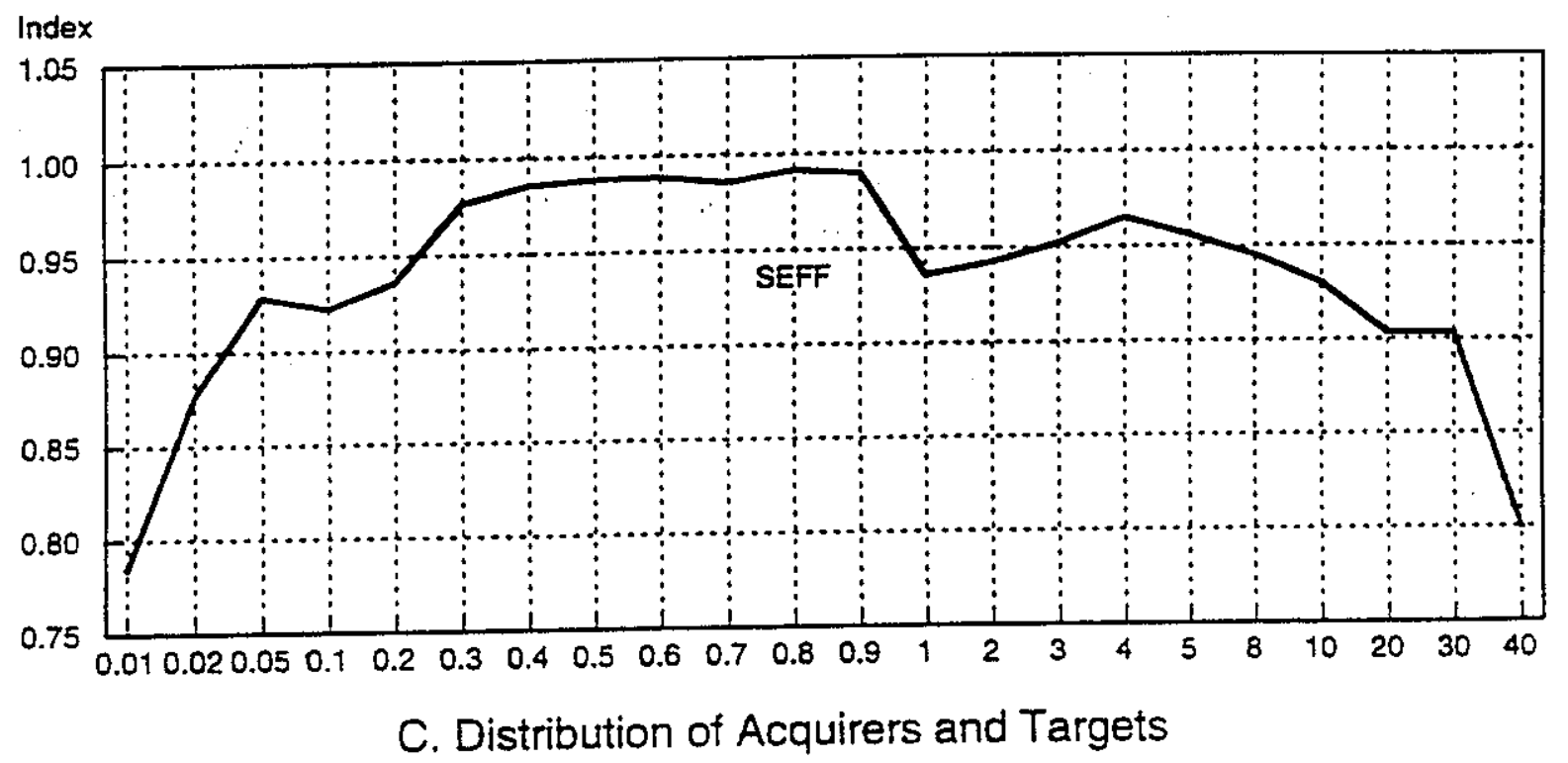

Proportion

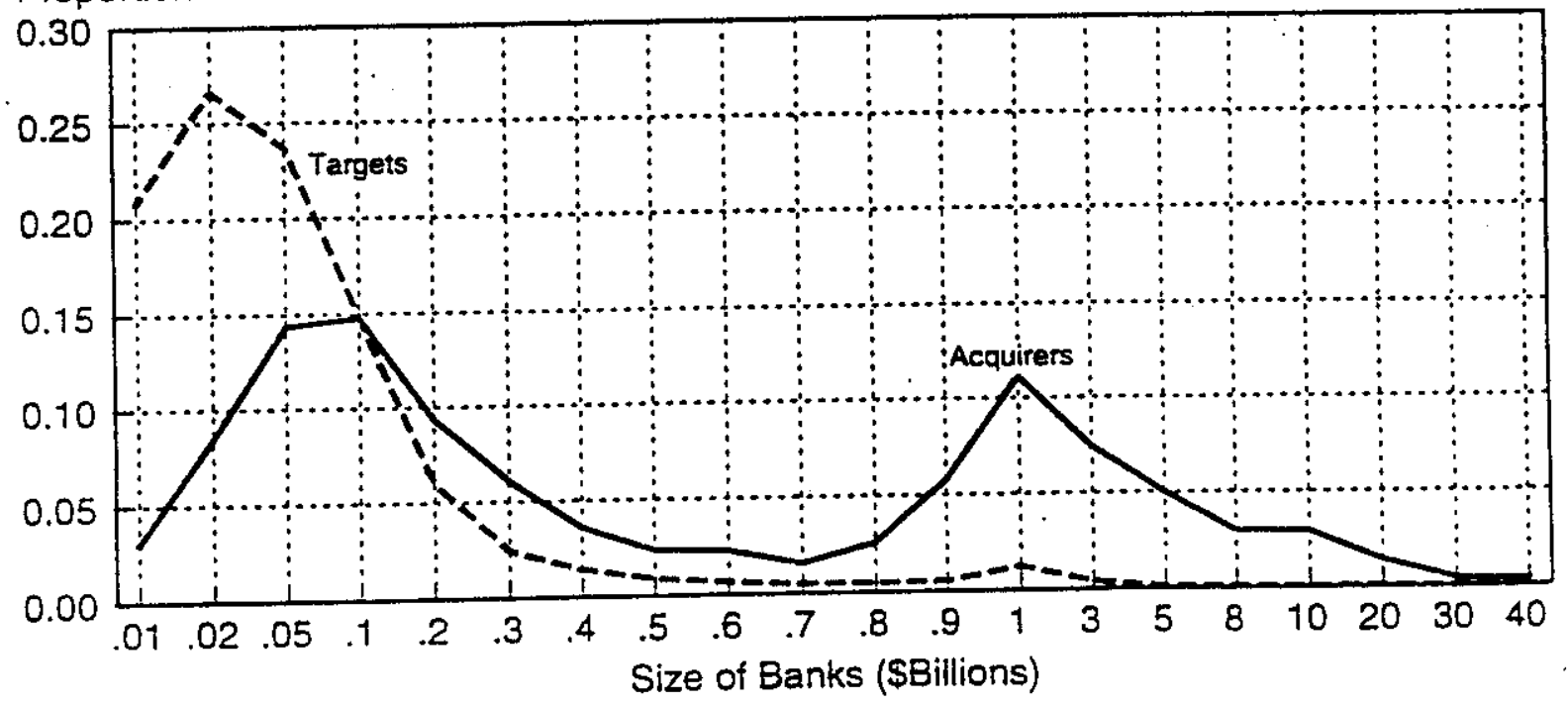


this case, we continue to treat all these mergers as a single transaction. But the type of merger activity is not clear any more. For convenience, the multiple merger was classified according to the type mode of the individual mergers. In the case of a tie, we used the size of targets to determine the type.

\section{THE POSTMERGER PERFORMANCE OF MERGER SURVIVORS}

We estimate the translog cost function for each year using call report information from 1984 to 1990 . For the sake of brevity, estimates of the translog model are not reported in the paper. Scores of X-efficiency and scale efficiency are computed using $\mathrm{XEFF}_{t i}(0.05)$ and $\mathrm{SEFF}_{t i}$ as defined by equations (5) and (7), respectively. Figure 1 presents the distribution of $\mathrm{X}$-efficiency and scale efficiency scores by asset size. The top panel shows, with the exception of large banks (over $\$ 10$ billion in asset size), X-efficiency is fairly constant across all other size groups. Berger (1993) suggests that the lower-than-average efficiency values for large institutions may perhaps be caused by sample bias. Since small banks dominate the sample, what appears to be X-inefficiency could be measurement error; that is, the globally fitted regression model may not correctly specify the cost structure of certain classes of banks, especially large institutions. To account for this possibility, we reestimated the translog specification using three different size groups. Although we discover a slight shift in the distribution of $\mathrm{X}$-efficiency scores, large banks are still found to be relatively inefficient compared with midsize and small banks. The middle panel of figure 1 shows the class averages for scale efficiency. In contrast to X-efficiency, scale efficiency is more variable across the different size groups. The shape of SEFF suggests that the optimal scale efficiency size lies in the neighborhood of $\$ 800$ million. The chart clearly shows that small banks (usually those with assets of less than $\$ 100$ million) and large institutions (those with assets of greater than $\$ 10$ billion) are considerably more scale inefficient relative to other institutions.

The bottom panel of figure 1 offers a preliminary look at the possible effect of mergers on X-efficiency and scale efficiency by graphing the size differential between targets and acquirers during the 1980s. The average asset size of acquiring banks is $\$ 1.8$ billion, while 
Table 2

Correlation of X-efficiency and scale efficiency with other financial variables

\begin{tabular}{lll}
\hline Financial Measures & X-efficiency & Scale Efficiency \\
\hline Return on Assets & 0.248 & 0.190 \\
& $(0.0001)$ & $(0.0001)$ \\
Noninterest Expenses & -0.269 & -0.244 \\
$\cdot$ & $(0.0001)$ & $(0.0001)$ \\
Total Expenses & -0.253 & -0.078 \\
& $(0.0001)$ & $(0.0001)$ \\
Nonaccrual Loans & -0.145 & -0.024 \\
& $(0.0001)$ & $(0.0076)$ \\
Assets-to-Employees & 0.163 & 0.063 \\
& $(0.0001)$ & $(0.0001)$ \\
Equity-to-Assets & 0.063 & -0.247 \\
& $(0.0093)$ & $(0.0001)$ \\
Management Rating & 0.133 & 0.183 \\
& $(0.0001)$ & $(0.0001)$ \\
Scale Efficiency & -0.057 & \\
& $(0.0001)$ & \\
\hline \hline
\end{tabular}

NOTES: Numbers in parentheses are p-values. All financial ratios are measured as percent of assets. For the management rating variable, the top rating is -1 and lowest rating is -5 . 
the average target's size is only about $\$ 0.13$ billion. About 90 percent of the targets are less than $\$ 200$ million in asset size. Acquirers are more evenly distributed, with only 49 percent being smaller than $\$ 200$ million. The large size differential is quite important because it suggests that the smaller targets are more likely to be scale inefficient than the larger acquiring institutions. On the other hand, targets would appear to have a similar or even better chance of being more $\mathrm{X}$-efficient than the bigger acquirers.

In comparison with traditional ratios, that is, return on assets and cost ratios, scale efficiency and $\mathrm{X}$-efficiency are relatively obscure measures of bank performance. Table 2 sheds some light on these intricate measures by presenting the correlation matrix between the efficiency measures and several standard financial ratios. An interesting finding is that $\mathrm{X}$-efficiency and scale efficiency are negatively correlated $(\rho=-0.057)$. The negative correlation means that $\mathrm{X}$-efficient firms are more likely to operate at a scale-inefficient point, suggesting the possibility that banks may regard X-efficiency and scale efficiency as substitutes. This behavior may particularly apply to independent community banks that operate in very small markets. Although these small banks operate at a scale-inefficient point by choice, they can compensate by being better at other facets of competition.

Overall, the correlation coefficients between efficiency and other financial ratios come up as anticipated. X-efficiency has a positive association with ROA $(\rho=0.248)$ and a negative correlation with the noninterest expense ratio $(\rho=-0.260)$, indicating that $\mathrm{X}$ efficient firms are on average more profitable and have lower operating costs relative to other banks. Moreover, X-efficient banks have less credit risk and are more productive in the sense of having a higher assets-to-employee ratio. The table also shows the relationship between the efficiency measures and a formal rating of bank management. This rating, derived from bank examination data, is the only available indicator of the bank's extant managerial proficiency. The correlation coefficient between the management rating and $\mathrm{X}$ efficiency is 0.133 and is statistically significant. Although the coefficient is not very high, we find it encouraging that $\mathrm{X}$-efficiency scores are related to independent bank examination 
Table 3a

Postmerger changes in X-efficiency

\begin{tabular}{|c|c|c|c|c|c|}
\hline \multicolumn{6}{|c|}{ Multiple Mergers } \\
\hline & & \multicolumn{2}{|c|}{ Level } & \multicolumn{2}{|c|}{ Rank } \\
\hline & & $\begin{array}{l}\text { Premerger } \\
\text { Mean } \\
\end{array}$ & Change & $\begin{array}{l}\text { Premerger } \\
\text { Mean }\end{array}$ & Change \\
\hline \multirow[t]{3}{*}{ BHC-Consolidation } & Acquirer & 0.788 & $-0.008^{*}$ & 46.50 & $-3.10^{*}$ \\
\hline & Pro forma & 0.787 & $-0.009^{*}$ & 46.25 & $-3.29 *$ \\
\hline & Control & 0.796 & 0.002 & 49.04 & -0.98 \\
\hline \multirow[t]{3}{*}{ Intrastate } & Acquirer & 0.789 & -0.002 & 46.84 & -2.31 \\
\hline & Pro forma & 0.790 & -0.002 & 47.73 & -2.07 \\
\hline & Control & 0.794 & $0.013^{*}$ & 48.25 & $2.78^{*}$ \\
\hline \multirow[t]{3}{*}{ FDIC-assisted } & Acquirer & 0.766 & $-0.026^{*}$ & 40.52 & $-8.40^{*}$ \\
\hline & Pro forma & 0.768 & $-0.024^{*}$ & 41.09 & $-8.10^{*}$ \\
\hline & Control & 0.779 & $-0.009 *$ & 44.74 & $-4.69^{*}$ \\
\hline \multirow[t]{4}{*}{ Overall } & Acquirer & 0.786 & $-0.008^{*}$ & 45.80 & $-3.47^{*}$ \\
\hline & Pro forma & 0.786 & $-0.008^{*}$ & 45.76 & $-3.45^{*}$ \\
\hline & Control & 0.793 & $0.004^{*}$ & 48.18 & -0.18 \\
\hline & NOBS & 786 & & 786 & \\
\hline \multicolumn{6}{|c|}{ Onetime Mergers } \\
\hline \multirow[t]{3}{*}{ BHC-Consolidation } & Acquirer & 0.812 & $-0.023^{*}$ & 53.024 & $-7.32^{*}$ \\
\hline & Pro forma & 0.807 & $-0.015^{*}$ & 52.07 & $-5.82^{*}$ \\
\hline & Control & 0.805 & -0.001 & 51.82 & $-1.55^{* *}$ \\
\hline \multirow[t]{3}{*}{ Intrastate } & Acquirer & 0.818 & $-0.015^{*}$ & 55.76 & $-5.64^{*}$ \\
\hline & Pro forma & 0.809 & -0.005 & 52.78 & $-2.56^{*}$ \\
\hline & Control & 0.800 & $0.009^{*}$ & 50.40 & $1.18^{*}$ \\
\hline \multirow[t]{3}{*}{ FDIC-assisted } & Acquirer & 0.792 & $-0.027^{*}$ & 47.87 & $-8.98^{*}$ \\
\hline & Pro forma & 0.766 & -0.002 & 40.72 & -1.84 \\
\hline & Control & 0.785 & $-0.003^{*}$ & 46.11 & $-2.44^{*}$ \\
\hline \multirow[t]{4}{*}{ Overall } & Acquirer & 0.808 & $-0.021^{*}$ & 52.56 & $-7.15^{*}$ \\
\hline & Pro forma & 0.795 & -0.007 & 48.89 & $-3.53^{*}$ \\
\hline & Control & 0.797 & 0.002 & 49.52 & 0.77 \\
\hline & NOBS & 395 & & 395 & \\
\hline
\end{tabular}

NOTES: The symbol $\left({ }^{*}\right)$ indicates statistical significance at the 5 percent level. Numeric $\mathrm{X}$-efficiency is defined by equation (5). Rank X-efficiency values are the ranks of the numeric values scaled between 0 and 100 . The premerger mean represents the average efficiency five to eight quarters before the merger. The change is the difference between the average efficiency five to eight quarter before the merger and the average efficiency nine to sixteen quarter after the merger. 
Table 3b

Postmerger changes in scale efficiency

\begin{tabular}{|c|c|c|c|}
\hline \multicolumn{4}{|c|}{ Multiple Mergers } \\
\hline & & $\begin{array}{l}\text { Premerger } \\
\text { Mean }\end{array}$ & Change \\
\hline \multirow[t]{3}{*}{ BHC-Consolidation } & Acquirer & 0.941 & $0.034^{*}$ \\
\hline & Pro forma & 0.937 & $0.039^{*}$ \\
\hline & Control & 0.920 & 0.024 \\
\hline \multirow[t]{3}{*}{ Intrastate } & Acquirer & 0.931 & $0.033^{*}$ \\
\hline & Pro forma & 0.923 & $0.040^{*}$ \\
\hline & Control & 0.911 & $0.018^{*}$ \\
\hline \multirow[t]{3}{*}{ FDIC-assisted } & Acquirer & 0.879 & $0.064^{*}$ \\
\hline & Pro forma & 0.854 & $0.089^{*}$ \\
\hline & Control & 0.851 & $0.059^{*}$ \\
\hline \multirow[t]{4}{*}{ Overall } & Acquirer & 0.930 & $0.037^{*}$ \\
\hline & Pro forma & 0.921 & $0.045^{*}$ \\
\hline & Control & 0.907 & $0.027^{*}$ \\
\hline & NOBS & 786 & \\
\hline \multicolumn{4}{|c|}{ Onetime Mergers } \\
\hline \multirow[t]{3}{*}{ BHC-Consolidation } & Acquirer & 0.904 & $0.052^{*}$ \\
\hline & Pro forma & 0.911 & $0.044^{*}$ \\
\hline & Control & 0.887 & $0.022^{*}$ \\
\hline \multirow[t]{3}{*}{ Intrastate } & Acquirer & 0.890 & $0.053^{*}$ \\
\hline & Pro forma & 0.899 & $0.044^{*}$ \\
\hline & Control & 0.890 & $0.023^{*}$ \\
\hline \multirow[t]{3}{*}{ FDIC-assisted } & Acquirer & 0.802 & $0.107^{*}$ \\
\hline & Pro forma & 0.807 & $0.102^{*}$ \\
\hline & Control & 0.847 & 0.052 \\
\hline \multirow[t]{4}{*}{ Overall } & Acquirer & 0.868 & $0.069^{*}$ \\
\hline & Pro forma & 0.875 & $0.062^{*}$ \\
\hline & Control & 0.876 & $0.031^{*}$ \\
\hline & NOBS & 395 & \\
\hline
\end{tabular}

NOTES: The symbol $\left({ }^{*}\right)$ indicates statistical significance at the 5 percent level. Scale efficiency is defined by equation (7). The premerger mean represents the average efficiency five to eight quarters before the merger. The change is the difference between the average efficiency five to eight quarter before the merger and the average efficiency nine to sixteen quarter after the merger. 
ratings of managerial efficiency. Using again the bank examination management ratings for a sample of OCC banks, DeYoung (1994) also finds that a large fraction of cost inefficiencies can be attributed to managerial inadequacy. Overall, these results are quite positive because they establish an intuitive link between the efficiency measures employed by this study and standard performance statistics.

\subsection{Postmerger Changes in Scale Efficiency and X-Efficiency}

The change in performance of the acquirer is measured in two ways: 1) against its own premerger performance, and 2) in terms of the pro forma bank. These measures provide differing but interesting viewpoints of valuation. The pro forma measure is perhaps more useful to regulators and banking analysts, who are chiefly concerned about the overall gains of mergers. Financial analysts and investors who own stock in the acquiring bank would also be interested in the own performance measure. For comparison purposes, we also calculated the average change for a control group. The control group consists of banks belonging in the same class size and located in the same state that were not involved in a merger for two years (eight quarters) before or after the quarter in which the merger took place. ${ }^{2}$. The change in efficiency represents the average efficiency over the period two to four years after the merger minus the average efficiency over the period of one year before the merger.

Table 3a summarizes the postmerger changes in $X$-efficiency (XEFF) and rank $X$ efficiency (RANKXEFF) defined by equations (6) and (7), respectively. Although the results on XEFF and RANKXEFF generally agree, changes in rank X-efficiency appear to be larger. This outcome is not surprising, because $\mathrm{X}$-efficiency ranks would tend to magnify the relative difference between banks. Overall, the findings suggest that multiple and onetime acquirers suffer a small decline $(-0.008$ and -0.007 , respectively) in pro forma X-efficiency after the merger. In terms of rank X-efficiency, acquirers realized about a 3.5 percent drop. By contrast, the control group appears to suffer smaller decreases in X-efficiency and, in

${ }^{2}$ We use five class sizes $(\$ 0-\$ 250$ million, $\$ 250-\$ 500$ million, $\$ 500-\$ 750$ million, $\$ 750$ $\$ 1000$ million, and over $\$ 1$ billion). 
the case of intrastate mergers, even shows a significant increase in X-efficiency. Overall, our analysis shows that, at minimum, the acquiring banks did worse in terms of $\mathrm{X}$-efficiency than did the control group.

As illustrated by figure 1 , if banks are assumed to produce on the same output expansion path as the scale-efficient bank, the optimal scale efficiency size is somewhere in the neighborhood of $\$ 800$ million. This means that, on average, a small or midsize institution growing through acquisitions should improve scale efficiency after the merger. The postmerger comparisons (table $3 \mathrm{~b}$ ) bolster this view by showing that multiple and onetime acquirers achieve moderate gains in scale efficiency in terms of their own performance and pro forma scale efficiency. For instance, multiple acquirers that engage primarily in intrastate mergers gain 4 percentage points in pro forma scale efficiency. Banks acquiring FDIC-assisted targets exhibit the highest potential for improvement gaining 8.9 percentage points in pro forma scale efficiency. Onetime acquirers again show an improvement in pro forma scale efficiency. Although it appears that consolidation has allowed acquiring banks to improve overall scale efficiency, we should note that the control group has also achieved considerable gains in postmerger scale efficiency over the same period. This result suggest an industry-wide effort to improve scale efficiency. Acquisition is but one of many possible ways to improve scale. Alternatively, small scale-inefficient banks can grow internally while large inefficient banks can simply downsize.

\subsection{Evaluating Changes in Profitability and Operating Costs}

Most empirical studies investigating the effectiveness of mergers and acquisitions focus primarily on simple financial ratios of profitability and operating cost. A Board of Governors staff study by Rhoades (1986) provides an extensive review of the earlier work. The earlier literature analyzed bank mergers during the 1960s and 1970s, a period which for the most part is not very pertinent because of the different regulatory environment. The rise in bank consolidation during the 1980 s has motivated a number of recent studies investigating the

postmerger profitability and cost efficiency of merger survivors [see Rhoades (1993) and 


\section{Table 4}

Postmerger changes in profitability and noninterest expenses

\begin{tabular}{|c|c|c|c|c|c|}
\hline \multicolumn{6}{|c|}{ Multiple Mergers } \\
\hline & & \multicolumn{2}{|c|}{$\begin{array}{l}\text { Return on } \\
\text { Assets }\end{array}$} & \multicolumn{2}{|c|}{$\begin{array}{l}\text { Noninterest } \\
\text { Expenses }\end{array}$} \\
\hline & & \multicolumn{2}{|c|}{ Premerger } & \multicolumn{2}{|c|}{ Premerger } \\
\hline & & Mean & Change & Mean & Change \\
\hline \multirow[t]{3}{*}{$\overline{\text { BHC-Consolidation }}$} & Acquirer & 0.132 & -0.011 & 0.897 & -0.001 \\
\hline & Pro forma & 0.114 & $0.007^{*}$ & 0.891 & 0.004 \\
\hline & Control & 0.257 & -0.018 & 0.738 & 0.002 \\
\hline \multirow[t]{3}{*}{ Intrastate } & Acquirer & 0.213 & 0.010 & 0.927 & $-0.021^{*}$ \\
\hline & Pro forma & 0.155 & $0.068^{*}$ & 0.928 & $-0.022^{*}$ \\
\hline & Control & 0.240 & 0.002 & 0.872 & $-0.023^{*}$ \\
\hline \multirow[t]{4}{*}{ FDIC-assisted } & Acquirer & 0.246 & $-0.071^{*}$ & 0.878 & $0.108^{*}$ \\
\hline & Pro forma & -0.178 & $0.353^{*}$ & 1.016 & -0.030 \\
\hline & Corrected Pro forma & -0.110 & $0.287^{*}$ & 0.970 & 0.036 \\
\hline & Control & -0.018 & $0.013^{*}$ & 0.817 & $0.169 *$ \\
\hline \multirow[t]{4}{*}{ Overall } & Acquirer & 0.172 & -0.010 & 0.905 & -0.004 \\
\hline & Pro forma & 0.097 & $0.065^{*}$ & 0.918 & -0.009 \\
\hline & Control & 0.222 & -0.008 & 0.793 & 0.007 \\
\hline & NOBS & 1105 & & 920 & \\
\hline \multicolumn{6}{|c|}{ Onetime Mergers } \\
\hline \multirow[t]{3}{*}{ BHC-Consolidation } & Acquirer & 0.161 & -0.054 & 0.910 & 0.076 \\
\hline & Pro forma & 0.161 & -0.046 & 0.926 & 0.054 \\
\hline & Control & 0.211 & $0.005^{*}$ & 0.803 & $-0.028^{*}$ \\
\hline \multirow[t]{3}{*}{$\overline{\text { Intrastate }}$} & Acquirer & 0.160 & 0.030 & 1.011 & 0.058 \\
\hline & Pro forma & 0.089 & $0.104^{*}$ & 1.017 & 0.058 \\
\hline & Control & 0.181 & $0.049^{*}$ & 0.802 & -0.005 \\
\hline \multirow[t]{4}{*}{ FDIC-assisted } & Acquirer & 0.203 & $-0.211^{*}$ & 0.899 & $0.117^{*}$ \\
\hline & Pro forma & -0.153 & 0.144 & 0.976 & 0.046 \\
\hline & Corrected Pro forma & -0.109 & 0.099 & 0.960 & 0.057 \\
\hline & Control & 0.117 & $0.042^{*}$ & 0.867 & -0.002 \\
\hline \multirow[t]{4}{*}{$\overline{\text { Overall }}$} & Acquirer & 0.172 & $-0.065^{*}$ & 0.946 & $0.081^{*}$ \\
\hline & Pro forma & 0.043 & $0.067^{*}$ & 0.975 & 0.052 \\
\hline & Control & 0.171 & $0.033^{*}$ & 0.823 & -0.011 \\
\hline & NOBS & 483 & & 410 & \\
\hline
\end{tabular}

NOTES: The symbol $\left({ }^{*}\right)$ indicates statistical significance at the 5 percent level. Ratios are measured as percents. The sample for noninterest expenses is smaller because operating costs are reported only after 1984 . The premerger mean represents the average efficiency one to four quarters before the merger. The change is the difference between the average efficiency one to four quarter before the merger and the average efficiency nine to sixteen quarter after the merger. 
Peristiani (1993). For an extensive survey, see Rhoades (1994)].

Although this paper is concerned primarily with efficiency, reexamining the effect of consolidation on bank profitability and costs proves useful. Again the comparison entails comparing the pre- and postmerger performance of the acquiring institution. We measure the premerger performance of banks by the average return on assets and the average noninterest expense ratio over the four quarters before the takeover. The postmerger performance is based on the average return on asset and the average noninterest expense ratio over the period two to four years after the merger - that is; quarters 9 through 16 after the merger.

As noted previously, FDIC-assisted transactions are quite different in comparison with standard mergers. : In the case of P\&A mergers, the FDIC takes some losses by allowing the acquirer to purchase a package of the failed bank's assets and assume the failed bank's liabilities. Under the total asset purchase and assumption method (TAPA), the acquiring banks must purchase and assume all the assets of the failing target. Of the approximately 1,000 assisted mergers, 660 were done by $P \& A$ and 130 were done by TAPA. The remaining bank failures were resolved through small loan asset purchases or resolved though a bridge bank. In a way, the pro forma and own performance estimates provide the outer bounds on bank performance. The own performance measure underestimates potential gains because it does not account for the premerger performance of the failed target. By contrast, pro forma comparisons overstate the improvement because they assume that all assisted mergers are done by TAPA. A simple way to correct this bias is by adjusting the pro forma measure to exclude the FDIC's reported loss on each transaction. The FDIC loss provides a fair proxy of the classified assets that were avoided by the acquirer. This adjustment is straightforward for financial ratios such as return on assets because these measures are additive in nature. Unfortunately, this approach is not very useful in revising the X-efficiency and scale efficiency measures.

Table 4 presents a summary of the postmerger changes in bank profitability and operating costs. Looking solely at the own performance of the acquiring bank, we observe a 
general decline in profits after the merger. The reduction in the surviving bank's profitability is sharpest among FDIC-assisted acquirers, indicating that the absorption of bankrupt targets is not without cost. The picture on profitability improves considerably when we consider the pro forma comparisons. This is particularly evident in FDIC-assisted mergers and intrastate mergers. Finally, we find that pro forma profitability is unchanged for BHC consolidations. This outcome is not surprising because banks owned by the same bank holding company organization are usually quite similar in terms of profitability.

Intrastate mergers are perhaps the most interesting group because proponents of mergers view them as the route by which the needed consolidation can take place. Overall, intrastate acquirers realize a moderate but statistically significant increase in pro forma return on assets after a merger. This finding suggests that intrastate acquirers are able to absorb unprofitable banks and improve the performance of the pro forma bank. Yet even after these significant gains, banks with multiple mergers have a lower postmerger return on assets than does the control group.

The standard pro forma comparison is less meaningful in FDIC-assisted mergers because usually in this case acquirers assume a portion of the target's assets. As expected, the corrected pro forma value, which takes into account the FDIC's loss, lies between the own performance and standard pro forma values. On average, the FDIC suffered a loss in about the 85 percent of the cases included in the analysis. The cost for each failure measured as a percent of the target's assets was about 20 percent. The corrected pro forma measure continues to show a significant gain in ROA. We should note, however, that acquiring banks engaging in FDIC-assisted mergers suffer a considerable deterioration in their own performance and are never able to regain their premerger profitability levels.

Turning to noninterest expenses, we find that intrastate acquirers experience a statistically significant improvement in noninterest cost. Banks participating in multiple intrastate mergers achieve a 2.2 reduction in pro forma noninterest expenses. At the same time, however, we also observe that the control group achieves almost exactly the same reduction in 
noninterest expenses.

$\mathrm{BHC}$ consolidations do not yield any significant improvements in operating costs after the merger. This is an interesting result because one would expect that $\mathrm{BHC}$ consolidations are not motivated by any of the usual reasons: improving diversification, increasing market share, or expanding intó new markets. More likely, intracompany mergers occur because the parent company is seeking to improve overhead costs. A premerger comparison of $\mathrm{BHC}$ consolidation partners shows some potential for improvement because acquirers are more cost efficient than targets. Moreover, given the shared management, it should be easier to cut costs after a $\mathrm{BHC}$ consolidation. In intrastate mergers, by comparison, it may be more difficult to achieve such managerial coordination because executives of the merging banks may squabble over the various reorganization issues. Despite the apparent advantages, $\mathrm{BHC}$ consolidations can yield meaningful benefits only if the acquiring bank engages in wholesale changes. By combining two independent banks, operation managers can pare down a lot of the duplication, but in intracompany consolidations, such cost savings might be limited because banks with common ownership are more homogeneous.

\section{DETERMINANTS OF CHANGES IN BANK PERFORMANCE}

Our analysis has shown that some merger survivors were able to enhance performance after the merger. However, these improvements were not unique: in most instances, the control group achieved similar gains. More important, however, we found that performance varied considerably among merger participants. In this section, we use regression analysis to analyze cross-sectional differences in performance. As in the univariate analysis, the dependent variables are defined by the changes in X-efficiency ( $\triangle \mathrm{XEFF}$ ), in scale efficiency $(\triangle \mathrm{SEFF})$, in profitability $(\triangle \mathrm{ROA})$, and in operating expenses $(\triangle \mathrm{NIEX})$. A large literature on profit and cost functions has already established that bank earnings and expenses are determined by several factors: on-balance-sheet risk, regional economic conditions, and other market conditions. These same factors are expected to play a significant role in the postmerger performance of acquiring banks. Ceteris paribus, merger survivors should realize 
lower profits after a merger if they have underestimated the target's credit risk exposure. Although the causality in the relationship between efficiency and credit risk is unclear, we would expect efficient banks to have a better credit risk profile.

The collapse of oil prices in the early 1980s serves as a vivid example of how exogenous economic shocks can severely strain the profitability of depository institutions. Nevertheless, a merger can be successful just because the survivor has the good fortune to be helped along by a strong regional economy. We would also anticipate that adverse macroeconomic shocks could have a negative impact on efficiency, although more subtle. We account for variations in regional economic conditions by including in the regression model the number of state business failures ( $\triangle \mathrm{BUSFAIL}$ ). Differences in the local market structure are measured by the growth in MSA deposits $\left(\mathrm{DEPOS}_{g}\right)$, the growth in MSA concentration $\left(\mathrm{CONC}_{g}\right)$, and the bank's growth in primary market share $\left(\mathrm{SHARE}_{g}\right)$. $^{3}$ These MSA regressors, however, come at a small cost because we lose all acquiring banks that operate outside metropolitan areas.

Bank-specific risk factors, in particular credit risk, play a critical role in determining bank performance, especially profitability. Credit risk should also be harmful to managerial efficiency as resources are drained away from more productive uses. To control for balance sheet risk, the regression model includes the changes in the loan ratio ( $\triangle \mathrm{LOAN})$, nonaccrual loans $(\triangle \mathrm{NACC})$, core deposits $(\triangle \mathrm{CORE})$, and large deposits ( $\triangle \mathrm{LARGE}$ ). Berger and Humphrey (1992) suggest that the relative quality of the target bank should influence postmerger profitability and efficiency. According to the efficiency hypothesis, an efficient acquirer can profit by restoring inefficient targets; the union of two badly managed banks, by

3 We estimate market concentration using the Herfindahl-Hirschman index. The primary market represents the MSA where the head office of the bank is located. The market share is measured by the ratio of the pro forma bank's deposits to total MSA deposits. Here, we use only the branches of the acquirer and targets that are located in the same primary market. 
Table 5

Explaining postmerger performance: Multiple and onetime mergers

\begin{tabular}{|c|c|c|c|c|}
\hline \multirow[b]{2}{*}{ Explanatory } & \multicolumn{4}{|c|}{ Dependent Variable } \\
\hline & $\triangle \mathrm{XEFF}$ & $\triangle \mathrm{SEFF}$ & $\triangle \mathrm{ROA}$ & $\triangle \mathrm{NIEX}$ \\
\hline CONSTANT & $\begin{array}{l}-0.0216 \\
(-1.26)\end{array}$ & $\begin{array}{l}0.0246 \\
(1.37)\end{array}$ & $\begin{array}{l}0.1149^{*} \\
(3.82)\end{array}$ & $\begin{array}{l}-0.3282^{*} \\
(-1.97)\end{array}$ \\
\hline$\triangle \mathrm{NACC}$ & $\begin{array}{l}-0.0046 \\
(-1.46)\end{array}$ & & $\begin{array}{l}-0.1135^{*} \\
(-8.54)\end{array}$ & $\begin{array}{l}0.0504^{*} \\
(7.34)\end{array}$ \\
\hline$\triangle \mathrm{LARGE}$ & $\begin{array}{l}-0.0011 \\
(-0.93)\end{array}$ & & $\begin{array}{l}-0.0010 \\
(-1.80)\end{array}$ & $\begin{array}{l}-0.0030 \\
(-1.22)\end{array}$ \\
\hline$\triangle \mathrm{CORE}$ & $\begin{array}{l}0.2270^{*} \\
(1.86)\end{array}$ & & $\begin{array}{l}-0.0175 \\
(-0.02)\end{array}$ & $\begin{array}{l}0.0047 \\
(0.92)\end{array}$ \\
\hline$\triangle L O A N$ & $\begin{array}{l}0.0012^{*} \\
(1.65)\end{array}$ & & $\begin{array}{l}-0.0090^{*} \\
(-2.43)\end{array}$ & $\begin{array}{l}0.0053^{*} \\
(3.01)\end{array}$ \\
\hline$\triangle B U S F A I L$ & $\begin{array}{l}-0.0006 \\
(0.09)\end{array}$ & $\begin{array}{l}0.0051 \\
(0.67)\end{array}$ & $\begin{array}{l}0.0334 \\
(1.029)\end{array}$ & $\begin{array}{l}0.0005 \\
(0.03)\end{array}$ \\
\hline DISTANCE & $\begin{array}{l}-0.2242 \\
(-1.05)\end{array}$ & $\begin{array}{l}-0.3345 \\
(-0.29)\end{array}$ & $\begin{array}{l}-2.803 \\
(-0.77)\end{array}$ & $\begin{array}{l}0.4822 \\
(0.27)\end{array}$ \\
\hline OVERLAP & $\begin{array}{l}0.0071 \\
(0.71)\end{array}$ & $\begin{array}{l}0.0441 \\
(1.60)\end{array}$ & $\begin{array}{l}0.0645 \\
(0.73)\end{array}$ & $\begin{array}{l}0.0061 \\
(-1.45)\end{array}$ \\
\hline $\mathrm{BANK}_{g}$ & $\begin{array}{l}0.0583^{* * *} \\
(5.94)\end{array}$ & $\begin{array}{l}0.1010^{*} \\
(3.13)\end{array}$ & $\begin{array}{l}0.2847^{*} \\
(2.34)\end{array}$ & $\begin{array}{l}-0.5277^{*} \\
(-10.1)\end{array}$ \\
\hline EMPLOY $_{g}$ & $\begin{array}{l}-0.0861^{* * *} \\
(-7.31)\end{array}$ & $\begin{array}{l}0.0235 \\
(0.48)\end{array}$ & $\begin{array}{l}-0.2182 \\
(-1.33)\end{array}$ & $\begin{array}{l}0.5283^{*} \\
(7.17)\end{array}$ \\
\hline MARKET $_{g}$ & $\begin{array}{l}0.0068 \\
(0.33)\end{array}$ & $\begin{array}{l}-0.0959 \\
(-1.44)\end{array}$ & $\begin{array}{l}0.4966^{*} \\
(2.39)\end{array}$ & $\begin{array}{l}0.0495 \\
(-0.45)\end{array}$ \\
\hline $\mathrm{CONCET}_{g}$ & $\begin{array}{l}0.0108 \\
(1.47)\end{array}$ & $\begin{array}{l}0.0047 \\
(0.15)\end{array}$ & $\begin{array}{l}-0.0586 \\
(-0.55)\end{array}$ & $\begin{array}{l}0.0100 \\
(0.21)\end{array}$ \\
\hline SHARE $_{g}$ & $\begin{array}{l}0.0114 \\
(1.55)\end{array}$ & $\begin{array}{l}0.0067 \\
(0.42)\end{array}$ & $\begin{array}{l}0.1202^{*} \\
(2.75)\end{array}$ & $\begin{array}{l}-0.0463^{*} \\
(-2.05)\end{array}$ \\
\hline $\mathrm{XEFF}_{d}$ & $\begin{array}{l}-0.0179 \\
(-1.18)\end{array}$ & & & \\
\hline $\mathrm{SEFF}_{d}$ & & $\begin{array}{l}0.0016 \\
(0.05)\end{array}$ & & \\
\hline $\mathrm{ROA}_{d}$ & & & $\begin{array}{l}0.4885^{*} \\
(3.39)\end{array}$ & \\
\hline $\operatorname{NIEX}_{d}$ & & & & $\begin{array}{l}-0.1057^{*} \\
(-1.91) \\
\end{array}$ \\
\hline$\overline{\bar{R}^{2}}$ & 0.126 & 0.112 & 0.559 & 0.667 \\
\hline NOBS & 438 & 101 & 127 & 103 \\
\hline
\end{tabular}

NOTES: The symbols $\left({ }^{*}\right),\left({ }^{* *}\right)$, and $\left({ }^{* * *}\right)$ denote statistical significance at the 10,5 , and 1 percent level, respectively. FDIC-assisted mergers were excluded. The operator $\Delta$ represents the change from before and after the merger. The premerger period for ROA and NIEX was defined from 1 to 4 quarters before the merger. For XEFF and SEFF, which are measured on an annual basis, the premerger period was 5 to 8 quarters before the merger. In both cases the postmerger period was defined 9 to 16 quarters after the merger. 


\section{(Table 5 continued)}

$\mathrm{ROA}=$ return on assets (percent)

NIEX = noninterest expense ratio (percent)

$\mathrm{XEFF}=\mathrm{X}$-efficiency as defined by equation (7)(decimal)

SEFF = scale efficiency as defined by equation (10) (decimal)

NACC = nonaccrual ratio (percent)

LARGE $=$ ratio of large deposits (percent)

CORE $=$ core deposit ratio (percent)

LOAN = loan ratio (percent)

BUSFAIL = state business failures (millions)

DISTANCE = distance between target and acquirer (projected radial coordinates)

OVERLAP = deposit overlap between target and acquirer (decimal)

$\mathrm{BANK}_{g}=$ growth of bank in terms of deposits (decimal)

EMPLOY $_{g}=$ growth in employment (decimal)

$\mathrm{XEFF}_{d}=$ premerger weighted difference in XEFF between target and acquirer (decimal)

$\mathrm{ROA}_{d}=$ premerger weighted difference in ROA between target and acquirer (percent)

$\mathrm{SEFF}_{d}=$ premerger weighted difference in SEFF between target and acquirer (decimal)

$\mathrm{NIEX}_{d}=$ premerger weighted difference in NIEX between target and acquirer (percent) 
contrast, is not expected to yield any benefits. An alternative interpretation to the efficiency hypothesis holds that acquirers can be weakened by the inefficiencies of the acquired bank. To evaluate the importance of relative performance, the regression model employs variables measuring the differences in X-efficiency $\left(\mathrm{XEFF}_{d}\right)$, scale efficiency $\left(\mathrm{SEFF}_{d}\right)$, profitability $\left(\mathrm{ROA}_{d}\right)$, and operating costs $\left.(\operatorname{NIEX})_{d}\right)$.

Another motive for mergers, often suggested by bank analysts, is that in-market combinations offer an effective way to decrease excess capacity by allowing acquirers to close overlapping branches. This means that the potential for success depends on the relative market location of targets and acquirers. A measure of branch overlap between target and acquirer (OVERLAP) is computed from the ratio of branch deposits located in the same county. The distance between targets and acquirers (DISTANCE), computed from their respective county midpoints, offers a more direct measure of geographic association. Finally, the postmerger willingness of acquiring banks to grow and restructure is measured by the acquirer's pro forma percentage growth in deposits $\left(\mathrm{BANK}_{g}\right)$ and pro forma increase in employment (EMPLOY ${ }_{g}$ ).

Table 5 presents the regression estimates for onetime and multiple mergers. As expected, credit risk, represented by the ratio of nonaccrual loans, is crucial to bank earnings and costs. Surviving banks that incur an increase in nonaccrual loans, either because of the merger or as a result of any other bad decision, suffer a substantial deterioration in postmerger profitability. A surge in nonperforming loans also leads to higher operating costs. The rise in costs stems from lost resources devoted to foreclosing bad loans, recovery costs, and other loan-restructuring expenses. Our analysis also shows that a higher loan-to-assets ratio increases operational cost because lending products are more labor intensive relative to other holdings such as securities and cash.

Bank growth is also a significant determinant of operating costs and profitability. Banks unable to control employment growth suffer a rise in operating costs after the merger. Recently, several bank consultants and analysts have argued that consolidations offer the most 
practical alternative to downsizing. Mergers entail a major restructuring of the participating banks and thus provide an opportunity for drastic cuts that otherwise would not be implemented. Many of the megamergers completed in the late 1980 s and early 1990 s have been accompanied by ambitious plans to restructure and cut costs. For instance, in 1992 Bank America Corporation declared that it would trim approximately 10,000 to 12,000 jobs after its merger with Security Pacific, a cut that represented more than 10 percent of the pro forma employment.

The profit and cost equations serve as a useful benchmark by confirming that risk factors generally have the anticipated effect. Unfortunately, this consistency is not so evident in the X-efficiency and scale efficiency regressions. Both regression equations have a low $R^{2}$ with just a few variables showing any statistical significance. One such variable is bank growth that exhibits a positive and statistically significant association with the postmerger $\mathrm{X}$-efficiency of merger survivors. This result implies that acquirers that continue to expand after a merger achieve a higher level of X-efficiency. In the same spirit, we find that merger survivors unable to contain employment growth suffer a loss in X-efficiency. Market overlap (OVERLAP) and the distance between the target and acquirers (DISTANCE), variables that were included to capture the effect of in-market mergers, are generally not significant. These results suggest that there are no apparent benefits to in-market mergers. A recent study by Rhoades (1993) also finds that horizontal (in-market) mergers during 1980-86 did not improve total cost. Bank analysts have touted in-market mergers as the most effective method of consolidation, contending that survivors can eliminate many of the overlapping branches. Although in theory horizontal mergers should allow acquirers to discard overlapping operations and branches, there is little evidence that surviving banks are doing so. Peristiani (1993) has found that merger survivors are reluctant to close branches after a merger. The study estimates the growth in branches by comparing the number of branches following the last merger with a pro forma level that encompasses all takeovers. This comparison reveals that in multiple mergers the number of branch offices increased by 
11 percent per year.

An interesting outcome of our regression analysis is the finding that the relative performance of targets and acquirers plays a significant role in the postmerger performance of merger survivors. The difference between acquirers and targets is particularly important in postmerger profitability and operating expenses. The positive coefficients on $\mathrm{ROA}_{d}$ and $\mathrm{SEFF}_{d}$ and the negative coefficient on $\mathrm{NIEX}_{d}$ suggest that acquiring banks would realize higher gains in profitability, scale efficiency, and operating costs if they absorb underperforming targets. These findings appear to suggest that mergers are more beneficial to acquiring: banks when the performance gap between targets and acquirers is wide. More precisely, mergers in which the acquirer is a much better performer than the target lead to significant improvements when compared to all other mergers.

\section{CONCLUSION}

This paper investigates the effect of mergers on the efficiency and financial performance of merger survivors. In particular, the study focuses on X-efficiency and scale efficiency. More comprehensive than earlier efforts, our study investigates all bank mergers that occurred between 1980 and 1990. The merger population is classified according to three basic categories: intrastate mergers, $\mathrm{BHC}$ consolidations, and FDIC-assisted mergers.

A pre- and postmerger comparison of merger partners reveals that surviving banks realize a small but significant decline in pro forma $\mathrm{X}$-efficiency two to four years after the merger. Therefore, it appears that during the 1980s, mergers were not beneficial to banks in terms of $\mathrm{X}$-efficiency. Our analysis shows that acquiring banks achieve moderate improvements in scale efficiency and profitability. These pro forma gains are stronger for multiple acquirers, especially those involved in FDIC-assisted mergers. However, the comparisons also reveal that in most instances the control group achieves similar improvements in bank performance. Finally, BHC consolidations do not appear to offer any benefits to the holding parent. This result suggests that the one-bank organization with numerous branches is perhaps not superior to a multibank holding structure. 
Regression analysis reveals that the profitability and operating cost performance of surviving banks after the merger is greatly influenced by balance sheet attributes and other bank characteristics. However, we observe no such factors influencing scale efficiency and $\mathrm{X}$-efficiency. Another important finding of the regression analysis is that in-market mergers yield no significant improvements in postmerger performance.

The question whether mergers can improve profitability, lower costs, and increase the efficiency of the banking sector has attracted considerable attention. Recent studies have been somewhat critical of consolidation, concluding that mergers are ineffective as a restructuring tool. Although our results are somewhat more favorable to mergers, we are not implying that all combinations are unconditional successes. Rather, we believe that, on average, banks participating in certain types of mergers may realize some benefits in scale efficiency, profitability, and operating cost. The degree of the postmerger success depends on the ability of surviving banks to avoid any unnecessary increases in nonperforming loans and on their ability to reorganize the acquired bank. Moreover, we should note that mergers are not the sole means of lessening overcapacity. As suggested by the analysis of a group of control banks that did not participate in mergers, banks can achieve the same end through internal cutbacks and reorganization. 


\section{REFERENCES}

[1] Berger, A.N., 1993, 'Distribution-free' estimates of efficiency in the U.S. banking industry and tests of the standard distributional assumptions, Journal of Productivity Analysis 4.

[2] Berger, A.N. and T.H. Hannan, 1989, The price-concentration relationship in banking, Review of Economics and Statistics 71, 291-299.

[3] Berger, A.N. and D.B. Humphrey, 1991, The dominance of inefficiencies over scale and product mix economies in banking, Journal of Monetary Economics 28, 117-148.

[4] Berger, A.N. and D.B. Humphrey, 1992, Megamergers in banking and the use of cost efficiency as an antitrust defense, Antitrust Bulletin 37, 541-600.

[5] Berger, A.N., W. Hunter, and S.G. Timme, 1993, The efficiency of financial institutions: A review and preview of research past, present, and future, Journal of Banking and Finance 17, 221-249.

[6] Demsetz, H., Industry structure, market rivalry, and public policy, Journal of Law and Economics 16, 1-9.

[7] DeYoung, Robert. "X-efficiency and Management Quality in Commercial Banks." Economic and Policy Analysis Working Paper 94-1, Office of the Comptroller of the Currency, 1994.

[8] Gilbert, A., 1984, Bank market structure and competition: A review, Journal of Money, Credit, and Banking 16, 617-645.

[9] Hunter, W.C., S.G Timme and W.K. Yang, 1990, An examination of cost subadditivity and multiproduct production in large U.S. banks, Journal of Money, Credit, and Banking 22, 504-525.

[10] Mester, L.J., 1987, A multiproduct cost study of savings and loans, Journal of Finance $42,423-445$.

[11] Noulas A.G., S.C. Ray and S.M. Miller, 1987, Returns to scale and input substitution 
for Large U.S. banks, Journal of Money, Credit, and Banking 22, 94-108.

[12] Peristiani, S.C., 1993, The effect of mergers on bank performance, in: Studies on excess capacity in the financial sector (Vol. I), (Federal Reserve Bank of New York), 89-118.

[13] Rhoades, S.A., 1986, Bank operating performance of acquired firms in banking before and after acquisition, Staff Study No. 149, Board of Governors of the Federal Reserve System.

[14] Rhoades, S.A., 1993, Efficiency effects of horizontal (in-market) bank mergers, Journal of Banking and Finance 17, 411-422.

[15] Rhoades, S.A., 1994, A summary of merger performance studies in banking, 1980-1993, and an.assessment of the "operating performance" and "event studies" methodologies, Staff Study No. 167, Board of Governors of the Federal Reserve System.

[16] Shaffer, S., 1993, Can mergers improve bank efficiency?, Journal of Banking and Finance $17,423-436$.

[17] Spindt, Paul A., and Vefa Tarhan. "Are There Synergies in Bank Mergers?" Working Paper, Tulane University, 1992.

[18] Spindt, Paul A., and Vefa Tarhan. "Performance Economies Associated With Small and Medium Sized Bank Mergers." Journal of Banking and Finance 17 (April 1993), $460-62$.

[19] Srinivasan, Aruna. "Are There Cost Savings from Bank Mergers?" Economic Review Federal Reserve Bank of Atlanta (March/April 1992), 17-28. 


\section{FEDERAL RESERVE BANK OF NEW YORK RESEARCH PAPERS \\ 1996}

The following papers were written by economists at the Federal Reserve Bank of New York either alone or in collaboration with outside economists. Single copies of up to six papers are available upon request from the Public Information Department, Federal Reserve Bank of New York, 33 Liberty Street, New York, NY 10045-0001 (212) 720-6134.

9601. Bartolini, Leonardo, and Gordon M. Bodnar. "Are Exchange Rates Excessively Volatile? And What Does 'Excessively Volatile' Mean, Anyway?" January 1996.

9602. Lopez, Jose A. "Exchange Rate Cointegration Across Central Bank Regime Shifts." January 1996.

9603. Wenninger, John, and Daniel Orlow. "Consumer Payments Over Open Computer Networks." March 1996.

9604. Groshen, Erica L. "American Employer Salary Surveys and Labor Economics Research: Issues and Contributions." March 1996.

9605. Uctum, Merih. "European Integration and Asymmetry in the EMS." April 1996.

9606. de Kock, Gabriel S. P., and Tanya E. Ghaleb. "Has the Cost of Fighting Inflation Fallen?" April 1996.

9607. de Kock, Gabriel S. P., and Tania Nadal-Vicens. "Capacity Utilization-Inflation Linkages: A CrossCountry Analysis." April 1996.

9608. Cantor, Richard, and Frank Packer. "Determinants and Impacts of Sovereign Credit Ratings." April 1996.

9609. Estrella, Arturo, and Frederic S. Mishkin. "Predicting U.S. Recessions: Financial Variables as Leading Indicators." May 1996.

9610. Antzoulatos, Angelos A. "Capital Flows and Current Account Deficits in the 1990s: Why Did Latin American and East Asian Countries Respond Differently?" May 1996.

9611. Locke, Peter R., Asani Sarkar, and Lifan Wu. "Did the Good Guys Lose? Heterogeneous Traders and Regulatory Restrictions on Dual Trading." May 1996.

9612. Locke, Peter R., and Asani Sarkar. "Volatility and Liquidity in Futures Markets." May 1996.

9613. Gong, Frank F., and Eli M. Remolona. "Two Factors Along the Yield Curve." June 1996. 
9614. Harris, Ethan S., and Clara Vega. "What Do Chain Store Sales Tell Us About Consumer Spending?" June 1996.

9615. Uctum, Merih, and Michael Wickens. "Debt and Deficit Ceilings, and Sustainability of Fiscal Policies: An Intertemporal Analysis." June 1996.

9616. Uctum, Merih, and Michael Aglietta. "Europe and the Maastricht Challenge." June 1996.

9617. Laster, David, Paul Bennett, and In Sun Geoum. "Rational Bias in Macroeconomic Forecasts." July 1996.

9618. Mahoney, James M., Chamu Sundaramurthy, and Joseph T. Mahoney. "The Effects of Corporate Antitakeover Provisions on Long-Term Investment: Empirical Evidence." July 1996.

9619. Gong, Frank F., and Eli M. Remolona. "A Three-Factor Econometric Model of the U.S. Term Structure." July 1996.

9620. Nolle, Daniel E., and Rama Seth. "Do Banks Follow Their Customers Abroad?" July 1996.

9621. McCarthy, Jonathan, and Charles Steindel. "The Relative Importance of National and Regional Factors in the New York Metropolitan Economy." July 1996.

9622. Peristiani, S., P. Bennett, G. Monsen, R. Peach, and J. Raiff. "Effects of Household Creditworthiness on Mortage Refinancings." August 1996.

9623. Peristiani, Stavros. "Do Mergers Improve the X-Efficiency and Scale Efficiency of U.S. Banks? Evidence from the 1980s." August 1996.

9624. Ludvigson, Sydney. "Consumption and Credit: A Model of Time-Varying Liquidity Constraints." August 1996.

9625. Ludvigson, Sydney. "The Channel of Monetary Transmission to Demand: Evidence from the Market for Automobile Credit." August 1996. 